\title{
THE ESTIMATION OF MOTILITY DURING REST OR SLEEP
}

\author{
BY \\ G. H. COX and E. MARLEY* \\ From the Professorial Unit, Maudsley Hospital, London
}

It has been suggested that motility during sleep bears a reciprocal relation to depth of sleep (Pai, 1950). Kleitman (1932) and Maliniak (1934) describe mechanical or pneumatic systems for determining sleep motility, and Kleitman refers also to a photoelectric device which interpolates movements from the frequency of interruption by the sleeper of a source of light directed on to the bed (Kleitman, 1944).

The effect of drugs on movement during sleep might therefore be utilized as one criterion of the value of hypnotics. Yet methods for measuring sleep motility have been disappointing, the apparatus being cumbersome, or by virtue of its activity likely to keep the subject awake, or, when none of these demerits were applicable, the results obtained were difficult to quantitate. It is not surprising that Lasagna, in a recent appraisal of the efficacy of hypnotic agents, relied upon a combination of direct observation of the subject at intervals during the night together with the patient's estimate of sleep (Lasagna, 1954).

The apparatus here to be described operates on simple electronic principles and provides a reliable objective estimate of the amount of movement while the subject is recumbent or asleep.

\section{Apparatus}

The instrument is based on that designed originally by Mr. W. D. Furneaux. This consisted of four plungers arranged to lie under the transverse and longitudinal dimensions of the bed, the caps at the upper ends of the plungers being adjusted to make contact with the under surface of the mattress wire only if the subject was recumbent. The lower ends of the plungers abutted on to microswitches operating on the make-and-break principle, all four being connected in parallel. A downward displacement of any of the plungers completed the circuit, the resultant potential operating a counter remote from the ward. Furneaux found a reasonable correlation between motility scores obtained on this bed and a nurse's rating of the patient's depth of sleep (Furneaux, personal communication).

* Present address: Department of Pharmacology, Royal College of Surgeons, Examination Hall, Queen Square, London.

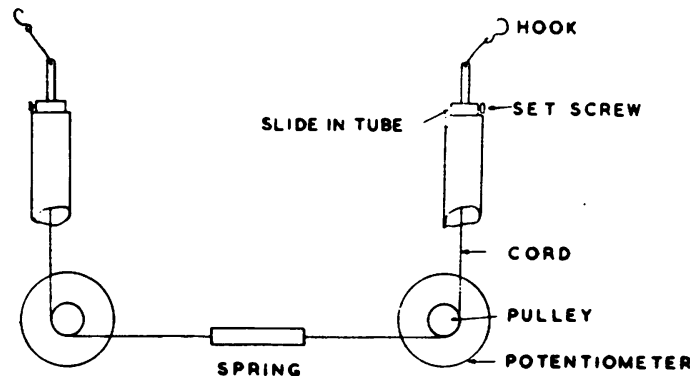

FIG. 1.-Semi-diagrammatic version of the apparatus mounted under the patient's bed.

We substantially modified this apparatus, some of its disadvantages being eliminated.

The plunger system was replaced by a cord drive (Fig. 1) connected above through an adjustable slide to a hook attached to the mattress wire. Below, the cord makes two revolutions (not shown in Fig. 1) around a brass pulley, as a single revolution was inclined to slip. Tension in the cord was maintained by a central spring. The slide (and cord length) is adjusted to the displacement of the mattress wire with the subject lying motionless in bed so that the relay just fails to operate. The microswitches were replaced by four standard linear carbon potentiometers (only two shown in Fig. 1), each attached to one of the brass pulleys. Movements at the pulley will therefore produce voltage differences at the potentiometer, the greater the movement the larger the potential difference. This voltage change was fed into the circuit shown in Fig. 2 and amplified at the $6 \mathrm{~J} 6$ valve to provide enough current to work the Veeder-Root counter from which scores were read hourly from 10 p.m. to 6 a.m. (total motility scores). Hourly scores were obtained, as it was hoped in a drug trial, to ascertain the earliest moment at which drug effects were detectable. A pen recorder could be incorporated in the circuit if required.

\section{Validation of the Bed}

It was essential to show that scores obtained with the bed were consistent, that is to say, that no variations that could be ascribed to outside influences (drugs) were being introduced by imperfect functioning of the apparatus. Secondly, while it was surmised that the bed measured movement, corroboration had to be obtained by correlating the motility scores with ratings of restlessness by 

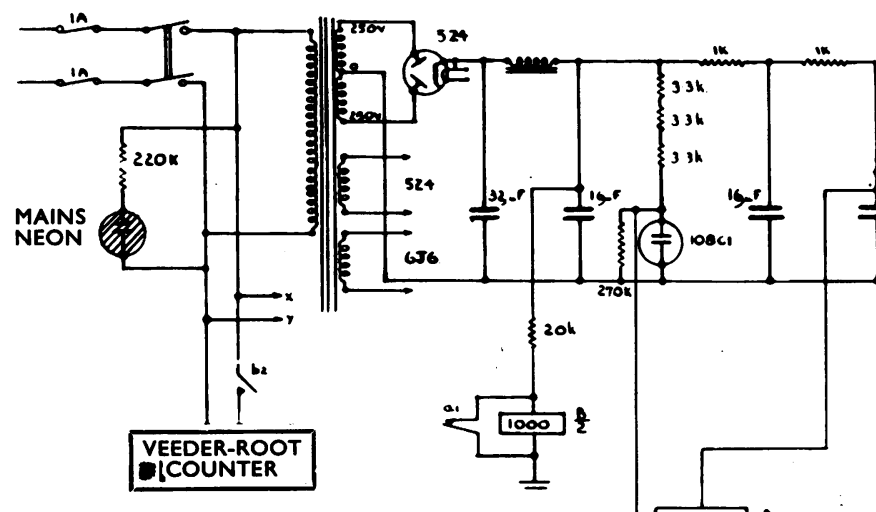
FIG. 2.- Circuit diagram for apparatus under the
bed and recording unit. $(\mathrm{P}=$ potentiometer.)

RELAY CONTACTS SHOWN N UNENERGIZED POSITION

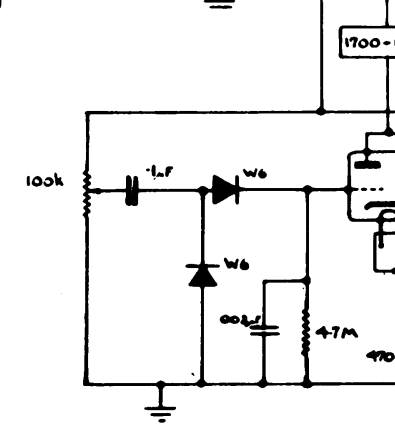

$\hat{\imath}$
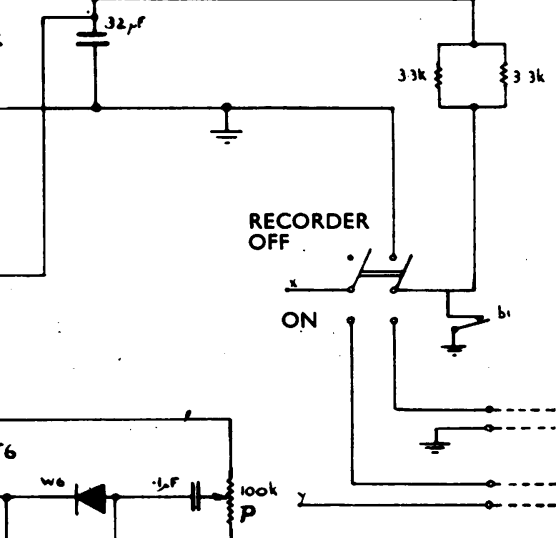

observers (nurses and patients), nurses' ratings of sleep or restlessness being traditionally more reliable than those of the patient.

\section{Reliability of the Apparatus}

This was tested by two investigations. The first consisted of analysing the total motility scores between $10 \mathrm{p} . \mathrm{m}$. and $6 \mathrm{a} . \mathrm{m}$. for seven patients who had been sleeping on the bed for at least two nights before beginning a five-day trial (Table I). This stricture was imperative, as unrepresentative high scores were always returned for the first night on the bed of the patient being tested. The seven patients were men aged 31 to 60 years. Four of the seven suffered from depressive illnesses, two were chronic alcoholics withdrawn from alcohol for at least four weeks, and the last was a patient with "psychogenic vomiting". Four of the seven continued their night hypnotic (200 mg. amylobarbitone sodium) throughoug the test phase, two received pentobarbitone sodium $200 \mathrm{mg}$., and one slept without medication. The results were subjected to analysis of variance. Only that part of the variance due to the difference between patients was significant $(F=3.92, \mathrm{P}<0.01)$. The difference between mean motility scores for the five consecutive nights can therefore be assigned to the difference between subjects and not to a significant variation in function of the bed during the test period.

The results for the second part of the investigation (Table I) derived from 11 patients undergoing a drug trial during which they received placebo (alternating with other drugs) on three nights during each of two consecutive series both extending over nine nights. Fuller

TABLE I

MEAN, RANGE, AND STANDARD ERROR OF THE MEAN OF MOTILITY SCORES DERIVED FROM SEVEN PATIENTS RECEIVING EITHER MEDICATION OR NO MEDICATION AND 11 SUBJECTS RECEIVING PLACEBO

\begin{tabular}{|c|c|c|c|c|c|c|c|c|}
\hline \multirow{2}{*}{$\begin{array}{l}\text { Number of } \\
\text { Patients }\end{array}$} & \multirow{2}{*}{$\begin{array}{l}\text { Motility } \\
\text { Scores }\end{array}$} & \multirow{2}{*}{$\begin{array}{l}\text { Indices } \\
\text { (units) }\end{array}$} & \multicolumn{6}{|c|}{ Nights } \\
\hline & & & 1 & 2 & 3 & 4 & 5 & 6 \\
\hline 7 & $\begin{array}{l}10 \text { p.m. to } \\
6 \text { a.m. }\end{array}$ & $\begin{array}{l}\text { Mean } \\
\text { Range } \\
\text { S.E. of Mean }\end{array}$ & $\begin{array}{l}51 \cdot 4 \\
9-100 \\
11 \cdot 5\end{array}$ & $\begin{array}{l}45 \cdot 3 \\
9-117 \\
12 \cdot 5\end{array}$ & $\begin{array}{c}38 \cdot 0 \\
20-65 \\
5 \cdot 9\end{array}$ & $\begin{array}{c}37 \cdot 7 \\
10-64 \\
6 \cdot 4\end{array}$ & $\begin{array}{c}56 \cdot 3 \\
12-116 \\
13 \cdot 4\end{array}$ & E \\
\hline \multirow{2}{*}{11} & $\begin{array}{l}10 \text { p.m. to } \\
2 \text { a.m. }\end{array}$ & $\begin{array}{l}\text { Mean } \\
\text { Range } \\
\text { S.E. of Mean }\end{array}$ & $\begin{array}{l}42 \cdot 4 \\
5-134 \\
11 \cdot 1\end{array}$ & $\begin{array}{l}41 \cdot 9 \\
5-117 \\
11 \cdot 1\end{array}$ & $\begin{array}{c}35 \cdot 0 \\
7-92 \\
8 \cdot 2\end{array}$ & $\begin{array}{c}33 \cdot 0 \\
1-82 \\
7 \cdot 9\end{array}$ & $\begin{array}{l}31 \cdot 3 \\
8-99 \\
7 \cdot 8\end{array}$ & $\begin{array}{c}34 \cdot 7 \\
6-110 \\
9 \cdot 8\end{array}$ \\
\hline & $\begin{array}{l}10 \text { p.m. to } \\
6 \text { a.m. }\end{array}$ & $\begin{array}{l}\text { Mean } \\
\text { Range } \\
\text { S.E. of Mean }\end{array}$ & $\begin{array}{c}77 \cdot 1 \\
15-236 \\
19 \cdot 6\end{array}$ & $\begin{array}{c}80 \cdot 1 \\
12-223 \\
20 \cdot 1\end{array}$ & $\begin{array}{l}67 \cdot 5 \\
9-152 \\
13 \cdot 8\end{array}$ & $\begin{array}{c}65 \cdot 6 \\
11-140 \\
12 \cdot 4\end{array}$ & $\begin{array}{l}62 \cdot 5 \\
8-176 \\
14 \cdot 0\end{array}$ & $\begin{array}{c}67 \cdot 2 \\
16-155 \\
12 \cdot 2\end{array}$ \\
\hline
\end{tabular}


FIG. 3.-Scatter diagram of total motility scores (10 p.m. to 6 a.m.) and nurses' rating for seven patients on five consecutive nights.

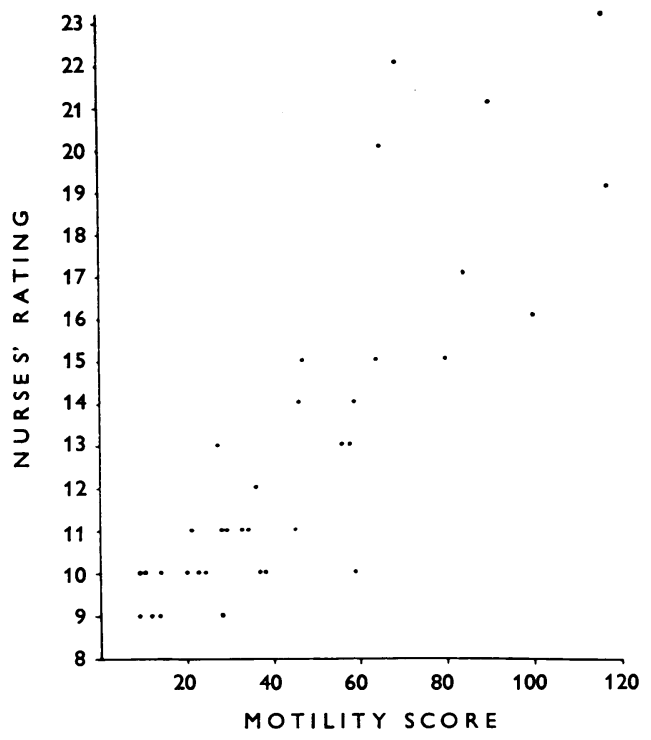

details are included in a further paper (Hinton and Marley, 1959). Total motility scores between 10 p.m. and 2 a.m. and $10 \mathrm{p} . \mathrm{m}$. and $6 \mathrm{a} . \mathrm{m}$. were examined by analysis of variance. The only significant contribution to the total variance for the scores between 10 p.m. and 2 a.m. came from the differences between patients $(F=8.84, \mathrm{P}<0.01)$ as was also the case for the motility scores between 10 p.m. and 6 a.m. ( $F=13.24, \mathrm{P}<0.001)$.

Thus the actual functioning of the bed as determined either from motility scores for part of (10 p.m. to 2 a.m.) or the whole of the night (10 p.m. to 6 a.m.) can be excluded as a significant source of difference in motility scores.

\section{Nurses' Rating and Motility Scores}

The motility scores were recorded hourly by one nurse for each of the original seven patients between 10 p.m. and $6 \mathrm{a} . \mathrm{m}$. At the same time another nurse was required to give an independent estimate of the patient's restlessness (sleep) during the prescribed hour. An arbitrary rating was adhered to, that of 1 for normal sleep, 2 for mild restlessness, 3 for moderate restlessness, and 4 if the patient should be excessively restless (8-32 = minimalmaximal night rating). Fig. 3 is a scatter diagram of the nurses' rating (ordinate) plotted against the respective nightly total motility scores of each patient (abscissa) during the five-day period. The correlation between the two was significant $(r=+0.81, \mathrm{P}<0.01)$. Thus movement as measured by the apparatus correlates highly with the nurses' ratings of movement.

\section{Patients' Rating and Motility Scores}

A "five-question" questionnaire (Fig. 4) was presented each morning to the seven subjects during the five-day
Fig. 4.-Sleep questionnaire completed by patients each morning. Figures in parentheses represent arbitrary rating for each item of the five questions.

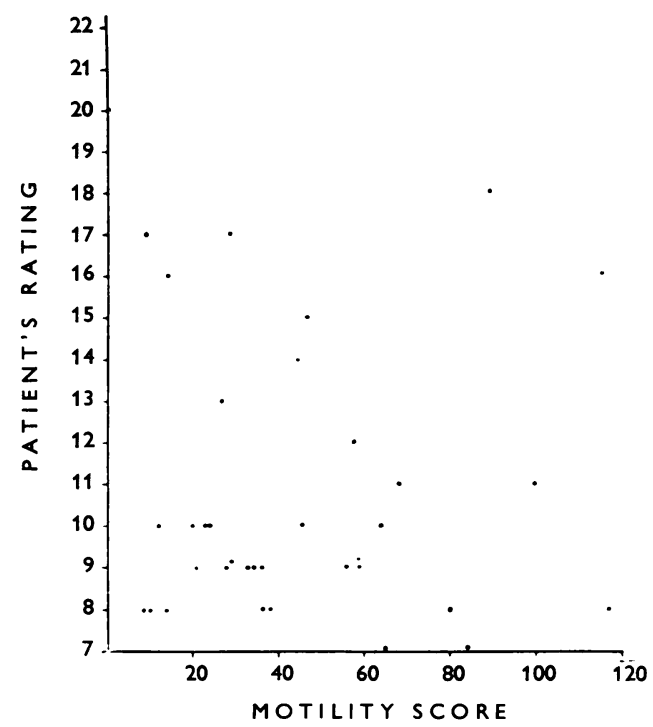

trial period. (This was evolved by Dr. D. L. Davies and had been used by him in a previous drug investigation.) The questionnaire was arbitrarily scored (figures within brackets) so that an evaluation might be derived from the patient's own estimate of soundness of sleep $(5=$ minimal, $18=$ maximal night rating). The scatter diagram relating the total individual motility scores ( $10 \mathrm{p} . \mathrm{m}$. to $6 \mathrm{a} . \mathrm{m}$.), for each of the five nights to the ratings derived from the patients is depicted in Fig. 5, there being no significant correlation between the two $(r=+0.04, \mathrm{P}>0.15)$.

\section{Discussion}

No one method used alone provides a satisfactory estimate of the hypnotic properties of drugs (Isaacs, 1957). However, the apparatus described above for recording movements during sleep or recumbency seems reliable and provides quantified data. The scores obtained were consistent if estimated over periods from 10 p.m. to either 2 a.m. or 6 a.m. Differences in mean motility scores that did emerge were ascribable to the differences between patients themselves rather than to discrepancies in serial functioning of the bed. As motility scores could be obtained at hourly intervals during the night, it was theoretically possible to study the time of onset of reduced movements, and, by inference, of the latency before significant drug action appears.

The apparatus required only weekly calibration and the incorporation of the valve and step-counter was a definite improvement. Small movements closely associated in time, but accompanied by subthreshold changes at the potentiometer, would 
Please underline the answer you wish to give to the following questions concerning your sleep last night.

I got off to sleep in 15 minutes

$I$ got off to sleep in 15 minutes

(5)

I slept for

0-2 hours

(1)

My sleep was

continuous
(2)

30 minutes

(4)

2-4 hours

(2)
(3)

(3)
45 minutes

(2)
(4)

60 minutes

(1)

6-8 hours longer than 8

(3)

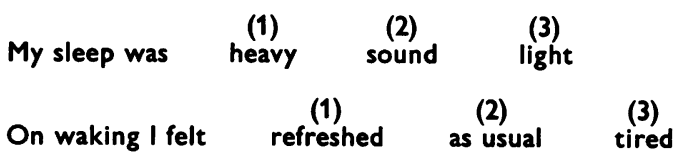

Make any other comments in the space below:- summate, which would have been impossible with the microswitch system on account of its inertia. However, as there is a slow leak of potential at the valve, intermittent small movements with spaced sub-threshold changes at the potentiometer will not summate. The other difficulty with the plunger and microswitch apparatus is that of the individual rolling on to his side and permanently depressing the microswitch, so creating a technical short circuit with no recording of further movement as long as he remains in that one position. This did not occur.

The high correlation between the nurses' rating of the patient's movement (and sleep) and the motility scores is striking, indicating that the apparatus was measuring restlessness. An objection could be that the rating of the patient's movement by one nurse and the recording of the appropriate motility score by another was not independent. The possibility of collusion, while feasible, is unlikely. Straus, Eisenberg, and Gennis (1955) relied on the nurses' estimation of the patient's sleep, regarding it as consistently superior to that of the patient.

There was no significant correlation between the patient's estimate of soundness of sleep and the motility scores. Two groups of investigators (Foltz, Dracos, and Gruber, 1955; Rushbrooke, Wilson, Acland, and Wilson, 1956) relied exclusively on the subjects' estimate of sleep. Imboden and Lasagna (1956) found there was a tendency for patients to underrate the effects of medication compared with the nurses' corresponding estimate.

One advantage of using motility as an index of sleep is that it is a continuous objective recording, in contrast to nurses' ratings of sleep which are subjective and intermittent. Little cooperation is required from the patient, a fact of importance if patients with psychiatric illnesses are included in the drug trial.
Fig. 5.-Scatter diagram of total motility scores (10 p.m. to 6 a.m.) and patients' rating for seven patients on five consecutive nights.

\section{Summary}

A method for measuring motility during sleep or recumbency is described.

Consistent results were obtained from one group of patients receiving placebo and from another taking either hypnotics or no medication.

Such differences in mean motility scores as did occur were ascribable to the differences between patients rather than to discrepancies in serial func tioning of the apparatus.

The nurse's independent estimate of the patients' motility and sleep correlated highly with the motility scores.

The patient's estimate of the soundness of his own sleep did not tally with the motility scores.

We take pleasure in thanking Professor A. J. Lewis, whose suggestion it was to use motility as an index of sleep in psychiatric patients, Dr. D. L. Davies for his ready interest and encouragement, Dr. A. E. Maxwell for invaluable statistical advice, the nursing staff of Ward 4, particularly Sister H. Hynes and Nurse D. Hodge, and Mr. D. A. Green for photographing the stencils.

\section{REFERENCES}

Foltz, E. L., Dracos, F., and Gruber, C. M. (1955). Amer. J. med. Sci., 230, 528 .

Hinton, J. M., and Marley, E. (1959). J. Neurol. Neurosurg. Psychiat., 22.

Imboden, J., and Lasagna, L. (1956). Bull. Johns Hopk. Hosp., 99.

Isaacs, B. (1957). Lancet, 1, 556

Kleitman, N. (1932). Proc. Soc. exp. Biol. (N.Y.), 29, 389

(1944). Medical Physics. Ed. O. Glasser. Vol. 1, p. 1433. Year Book Publishers, Chicago, Illinois.

Lasagna, L. (1954). J. Pharmacol, $111,9$.

Maliniak, S. (1934). Arch. psychol., 24, 177

Pai, M. N. (1950). Recent Progress in Psychiatry. Ed. G. W. T. H. Fleming Vol. 2, p. 590 . Churchill, London.

Rushbrooke, M., Wilson, E. S. B.. Acland, J. D., and Wilson, G. M. (1956). Brit. med. J., 1, 139 .

Straus, B., Eisenberg, J., and Gennis, J. (1955). Ann intern. Med., 42, 574. 